\title{
The Narrative Construction of Chinese Animation from the Perspective of Adolescent Audience
}

\author{
Hongya Zhou \\ School of Art and Design \\ Xihua University \\ Chengdu, China 610039
}

\begin{abstract}
Since the new century, the new generation of "post 2000" audience cultivated by the Chinese animation are gradually entering adolescence, so continuing to grasp the viewing preferences of this group and adapting to the market demand of a higher level is an important means for Chinese animation to achieve the continuation of influence and sound and comprehensive development. Based on the theme narrative theory, this paper takes contemporary adolescent as object and tries to find the way out and direction of sustainable development of Chinese animation in the fierce market competition through the study of the narrative theme, role shaping, narrative carrier and the cultural inheritance.
\end{abstract}

Keywords-Chinese Animation; adolescent; narrative

\section{INTRODUCTION}

After the glory of "Chinese school", under the dual role of industrialized development road and policy tilt, Chinese animation once again ushered in the rapid development period. Many outstanding works emerged and cultivated a large number of faithful fans of the new generation "post 2000". As the group gradually enters adolescence, their physical, psychological and living conditions have undergone great changes. The childish narrative means generally chosen by Chinese animation is no longer able to meet their needs, so the viewing emotion established for many years began to appear alienated. Therefore, the narrative construction of animation that takes care of the times, complies with the needs of adolescent audience, and has the function of cultural heritage is of great significance to the continuous and healthy development the Chinese animation.

\section{The New GENERATION OF "FANS" OF ChINESE ANIMATION}

The birth of Chinese animation can be traced back to the 1920s, followed by the establishment of the new China, and then the "Chinese school" that is formed and growing under the guidance of "nationalization" led the development of Chinese animation for three decades. In creation of worldrenowned brilliant achievements, it cultivated the three generations of Chinese animation audience groups including "post 1950", "post 1960", and "post 1970". However, with the continuous deepening of reform and opening up, the social environment and economic order began to undergo earth-shaking changes. When the original animation creation under planned economic system entered the market economy, it began to appear big shrinking since it was unable to adapt to the viewing needs of audience under the changes of the times. Both quality and quantity cannot be compared with the previous achievements. Coupled with the large-scale "invasion" of animation culture from the United States, Japan and other countries, Chinese animation have no place to stand, which completely lost the competitiveness, as well as the audience base of the two generations of "post 1980" and "post 1990". Basically, putting aside the external cause of weak means of market operation, the conservative, single animation narrative means with the form bigger than the content is an important factor that causes Chinese animation text to lose its vitality.

Since the new century, after the stages of resistance to the market economy, confusion and exploration, Chinese animation once again usher in the rapid development period under the dual role of industrialization and policy tilt. From the "3000 Whys of Blue Cat" that swept the mainland of China, to the "Pleasant Goat and Big Big Wolf" that got popularity among big streets and small alleys, and then to the "Boonie Bears" that occupied the market rapidly, and films like "Seer", "Roco Kingdom", "Mole Manor", and "GGbond", Chinese animation began to retrieve the market that it has been handed over to others' hand. The new generation of "post 2000" who are born in the same period are filled with those animations when they have the ability to watch, so they became the the first batch of "actual" audience of Chinese animation culture after reform and opening up in real meaning. And based on this childhood companions, their emotion and loyalty to Chinese animation is much higher than the "post 1980" and "post 1990" generations who are deeply impacted by animation of Japan and the United States.

\section{AN ANALYSIS OF THE CHARACTERISTICS OF ADOLESCENTS UNDER THE HISTORICAL BACKGROUND}

Adolescence is a period of human development process between childhood and adult. From the perspective of physiological and mental development, it generally refers to the group of people at age the above 13 and under 20 . Because everyone has to go through the adolescence of human during this time period, and most people are students, 
they have the distinctive characteristics different from that of any other stage of life. Because "post 2000" born after the new century are exposed in the living environment where changes are taken place rapidly, with fresh things emerging constantly, and especially the online media develop rapidly, they also show distinctive personality different from the adolescents in other times.

\section{A. Two Major Tendencies of Character}

Similar to some of "post 1980" and most "post 1990", "post 2000" audiences are mainly the only child. The superior family life from childhood contributed to their unique characteristics, with both the strengths of selfconfidence, rich knowledge and unabashed individuality, and the weakness of selfishness, delicacy, the lack of sharing spirit, poor resistance to blow, and weakness in communicating with people. Therefore, in the comprehensive role of internal and external effect, two groups with distinctive character of "outgoing and swanking group" and "introverted and ordinary group" are formed.

"Outgoing and swanking group" generally have all the characteristics of extroverted personality such as good communication and strong expressive force as well as some prominent character orientation of adolescent including passionate blood, desire to excel over others, blind arrogance and even reversion, so it is particularly important for them to drain surplus "energy" through appropriate methods.

"Introverted and ordinary group" generally have the strengths of introverted personality like higher intelligence, cautiousness, deep consideration and so on, while their weakness of self-abasement, anxiety, poor communication, emotional fragility, and the lack of security are amplified at this stage, so looking for the spirit strength and developing self-confidence are the problems they need to focus on.

\section{B. Idol Worship Phenomenon}

Idol worship is the phenomenon of extreme belief in human life, which produces the halo effect through peoples' exaggerated social cognition of idols, and sanctifies and mystifies their behavior [1]. When idols carry the human's hope, they will show the characteristics of transcendence, and then they will be given the spiritual functions of reposing the hope, guiding action and soothing the mind by the human. [2] Because adolescents have just gone through the relatively simple childhood, their physiology and mentality are changing rapidly. They begin to try to get rid of their parents to face the society independently and find their own position, but limited life experience and shortage of experience often make them at a loss, so in this process it becomes their important life composition to find the third-party inner sustenance and worship goals. Stars, great men, industry elites and even animation images may become the object of their worship and imitation, so crazy groupies, prosperous COSPIAY performances, as well as hot, obsessed and even extreme attitudes become the normality of this group of people.

\section{Great Network Dependence}

Since network rose in China in 1990s, it has integrated into every corner of society with a very rapid development trend. In recent years, it has become an indispensable part of people's lives with the sudden emergence of mobile Internet. But accompanied by this historical process, "network dependence" has become a very prominent social phenomenon in China. Due to the impact of network environment from childhood and the immature stage of adolescent, "post 2000" generation become the focus group of "network dependent". Almost all the contents of their lives including study, social activities, and entertainment can be completed in the network. Their possessing personal learning machines, mobile phones, IPAD and other mobile network terminals earlier than any other age groups further strengthens and facilitate this trend.

\section{The Lack of Knowledge of Traditional Culture}

The rapid development and transformation of the social environment, continuous emergence of foreign and new things, and weak and missing protection and heritage make the situation of traditional culture in China not optimistic, since the fine national heritage and excellent culture cultivation deposited from history become thin and fragile. When the adolescent group enjoys the rich material brought by reform and opening up, their spirit are influenced by the harmful culture of money worship, hedonism, and extreme liberalization with various "pro-others groups" like Koreaphile, Japanophile, pro-America and pro-Europe filled in our society, which leads to the lack of good atmosphere and environment for the understanding of the traditional culture including benevolence, righteousness, ritual, wisdom and integrity. The blunt preach of book and formal means not only produce little effect, but also push the traditional culture to an embarrassing situation of conceptualization, marginalization and amusement.

\section{NARRATIVE CONSTRUCTION OF ANIMATION BASED ON "PERSPECTIVE OF AdOLESCENT"}

Different times create different characteristics of the times and culture, and these will form a two-way relationship of mutual influence and mutual adaptation with the people living in it. If the reemerging Chinese animation wants to occupy more initiative and advantages in the market built elaborately, the key lies in transformation of narrative perspective from childishness to the level of adolescent.

\section{A. The Realistic Care of Narrative Text - The Excavation of School-based Theme}

"Many types of movies are targeted at specific audiences, such as the films about growth for adolescent, action adventure film mainly for men ... ... ", which clearly shows the realistic care meaning of films and television programs including animation in addition to entertainment. [3] As the famous animated filmmaker Yoshihiro Yoshihara explained for the forming reason of the Japanese cartoon atmosphere: "the habit of watching animation of Japanese is naturally formed, since people can find the solution to the problem 
from the animation works and find the courage and confidence to survive in the relaxed and happy atmosphere!"

Experienced campus life of many years, exchanges between adolescent and society become more and more wide, peers and partners have become very important social relations in their social interaction. Their learning, words and deeds, hobbies, and dressing are influenced mutually, and they face various problems of relationships with teachers, classmates and the opposite sex together. At the same time, the relationship between adolescents and the family is gradually alienated. They begin to doubt about the authority of their parents, and even make rebellious behavior with a strong and immature independence sense. In view of this feature, the theme that follows the ideology of adolescents, reflects the campus life of adolescent, explores the campus friendship, campus ideals, relationship between the opposite sexes, and relations between teacher and student will get their general recognition. However, in face of the huge market, this kind of theme has been quiet for a long period of time in China, except the first campus music theme work in China "Crazy for songs" jointly launched by Shanghai Animation Film Studio and Shanghai Television Station in 2002. Some latecomers like "The Dreaming Girl", "Life in the Clouds" and "green campus" have not attracted wide attention because of the thin narrative means. Looking at Japanese animation, this type of works have occupied a lot of proportion, forming the parallel work groups including science fiction, fairy tale, and detective, such as "SA top student", "Shugo Chara", "Keion", "Slamdunk","A Happy Family", which are well-known masterpiece of such types. When exploring the text of these excellent works, it will be found that although they are within the scope of the campus theme, they often mix various types of elements like magic, funny, sports, and love, which greatly enhances the fun and wonders of narrative text, and inspires the audience in fascinating plot and fantasy context to guide them in dealing with the increasingly complex problems of life. In face of the growing "post 2000" generation, Chinese animation should also strengthen the excavation of this theme, and constantly create new and diverse works to meet the huge market demand. It is worth mentioning that the industry has begun to pay attention to this point. For example, in recent years, the works like "Daily routine of girls' dormitory", "Lu's time", "Tea! No.2 Middle School", "monster list" and "absolute field" in network platform are useful exploration in this field; On July 6th, 2017, the news that Penguin film and television, Shanghai Animation Film Studio and Fuxi film and television jointly announced the official resumption of "crazy for songs" rekindled the youth dreams of a lot of fans. These positive signals are bound to promote the campus theme creation to enter a new stage, which will have a positive impact on the entire animation industry.

\section{B. The Proper Arrangement of the Narrative Core- "Round" and "Flat" Role Shaping}

Based on the realistic action and the target demands of fullness of the film, whether the new work or the reconstruction of the classic works must pay attention to meet the demands of the two different adolescent groups with different personalities including "outgoing and swanking group" and "introverted and ordinary group" in the role of shaping, and deal with the drama relationship between "round role" with rich character and "flat role" with single character.

With the comprehensive and rapid growth and change of muscles, bones and other organizations, the worship, dependence and desire for the strength and limits of human body lead "outgoing and swanking group" to have blood boil compared with "introverted and ordinary group" and the heroic roles with physical advantages as dominate are very attractive to them. When "introverted and ordinary group" begin to show a strong desire to explore and seek knowledge to the outside world, they can often use abstract thinking and theory to infer causal relationship and better deal with complex information or data, so the heroic role with profound intellectual advantage as the magic weapon can win their worship. However, if the protagonist only has the unilateral feature of flesh or wisdom, he will show a clear "flat" color. Therefore, other elements should be added to such roles based on a strong feature to ensure that it is in a dynamic process of constantly enriching and growing, and thus take the main task of promoting the development of the plot. This is like the fact that the warm-blooded heroes such as One Piece and Naruto also have good resourcefulness, while the roles with high IQ represented by Conan also have the "narcotic gun" to subdue the enemy. At the same time, as the supplement for further enrichment and promotion of the plot, supporting roles will act as typical "flat roles." Their character is single and the goal is simple. They are the role groups with different personality tendencies created together with the protagonist, so as to meet the spiritual needs of different audiences. If Chinese animation film want to continue to catch the eyes of "post 2000", in addition to the upgrade of narrative text, they should transform the current approach of shaping the protagonist by "flat roles" to shaping by "round roles" and reasonably arrange the proportion of two roles, which is the key to enrich the whole narrative core and facilitate the continuous emergence of animation star. In this respect, the "Boonie Bears" series is one of the successful practitioners. Although its animated TV series has been aimed at the younger audience under the age of 12, the creation of big film significantly improves the narrative means, leading to people of higher age including adolescent can also get a pleasant viewing experience. This kind of "growing up processing" approach to the childhood classic, gives richer narrative levels to the work, so that the animation characters grow with the audience in reality, achieving the purpose of continuing the idol effect of animation roles. Another example is the accidental and inevitable success of "Monkey King: Hero Is Back ", which let us see the charm of the role with vitality once again as well as the urgent spiritual needs for Chinese animation star of the audience.

\section{The Richness of Narrative Carrier - Network-centered Cross-media}

Media is the platform where all the narrative must be attached. Animation needs to be attached to the platforms 
like film and television to play its effect from the beginning because of its dynamic properties. In recent years, with the rapid development of the network and other media, it has become a major trend to use the advantages of various media and specific audience to make cross-media cooperation.

At present, there are two kinds of successful cross-media modes in the creation of childish animation in China. The first is represented by "Pleasant Sheep" and "Boonie Bears" series, which completes the accumulation of the audience through the long-term TV broadcast and then starts to excavate more commercial space in the field of film at the right time; the second is represented by "SEER" and "Roco Kingdom" series, which takes the online community game as a starting point, and ultimately forms the benign development pattern with the Troika of online games, television and film going hand in hand. Aiming at the special characteristics of adolescent, the way with the network media as center is more suitable. From the rise of a large number of video websites such as Tencent, iQIYI, Youku Tudou, Sohu, LETV, bilibili and AcFun and so on, to the emergence of network animation represented by "Miss Puff" and "One hundred thousand bad jokes", to the concept of "quadratic element economy", development of animation based on the online media has initially formed the development trend linking with comics, games, real film and television, and network animation therefore is regarded as the most important direction that changes the pattern of animation industry in China. Taking "One hundred thousand bad jokes" as an example, it started from the serial network comics on "U17" platform since 2010, and after the animation in 2012 it stirred up viewing boom. Then it became a dark horse of animated film market after the successful release of the first big film by the end of 2014 and the mobile game with the same name came online in 2015 . The second big film in 2017 became the Chinese animation film with the highest box office in summer. The precise positioning for the teenage netizen not only makes "One hundred thousand bad jokes" become the biggest beneficiaries, but also fully verifies the vitality and sustainability of the network model. On August 11, 2017, the first online animated film "The storm of star travel Familia" came online in IQIYI video website. This blood animation aiming for the adolescent harvested over 8 million amount of play within the 8 hours on the first day, and completed the historic breakthrough of 20 million amount of play after 3 days online, which created a good start for the network publishing of animated film. The role of network media in the development of animation will become increasingly obvious in future, so it will be more important to grasp the network using habits, aesthetic needs and hobbies of adolescent, and provide quality animation works for them in the context of the large network culture. And the radiation and diffusion centering on network to the other media will also be an irresistible trend in line with the development of the times.

\section{The Connotation of Narrative Function - Inheritance of National Culture}

Cultivation of the sense of national pride and cultural identity of adolescent is related to the fate of the whole country and nation in the future, so the cultural dross of other countries should not be the decisive factor leading the formation of the "three outlooks" of the adolescents. To change this situation requires a unified change and cooperation of all links of society, and animation works should also play their own advantages, to assume the important task of cultural heritage.

First of all, we should find the values and emotions that are universally recognized by all human in the world base on anthropology and sociology through analysis and summary. For example, the elements of praise of justice, advocation of freedom and song for kinship that have high probability in the animated works of the United States in fact are concepts that exist in every country and nation and are praised highly, but because of the strong offensive of output of overall value of the United States, these universal values are covered with thick American brand. Chinese animation can flexibly apply and perfectly show these ideas in their own stories to acquire the understanding and recognition of adolescent audience simply. Secondly, we should flexibility contain the ideas advocated by traditional culture and the national characteristics that Chinese people should have in the narrative text, and show the particularity and superiority of national culture through intentional and unintentional reminder and role shaping to establish the "national hero" of faith for them. For instance, the items with Japanese characteristics such as kimono, katana, and sailor suit as well as the cultural representatives in spiritual areas like spirit of warriors, Cherry blossom culture, and survival idea that appear repeatedly in the Japanese animation works have a strong national attributes and connotation, becoming an important way of cultural output. In this regard, "The Legend of Qin", "Monkey King: Hero Is Back", "Big Fish \& Begonia" and other works have made a good example, so it is believed to lead a new round of "national" development wave of Chinese animation. Finally, no matter what kind of ideas transmission, we must completely change the simple sermon mode and single narrative means. We need to skillfully arrange the narrative structure, fresh and plump route and role shaping based on seizing the psychological characteristics and spiritual needs of adolescent. Only in this way can we make the young audience really be attracted by Chinese animation, in order to eventually achieve the results and goals of cultural heritage in subtle influence.

\section{CONCLUSION}

It can be found that apart from the objective conditions of the special historical period, the "new comic book" led by Osamu Tezuka and the "respect" of the first generation of the audience are the most important two factors of the rise of the whole industry by studying the reasons for rise of Japanese anime culture. Current development of Chinese animation and "post 2000" generation who grow with it seem to reach the node with great historical similarity magically. They have walked through their own childhood hand in hand, so 
whether Chinese animation can continue to accompany the growth of "post 2000" generation on the road ahead is closely related to the pros and cons of narrative.

\section{REFERENCES}

[1] Yue Xiaodong, Yan Fei. A summary of the Series of Adolescents' Idol Worship (Part One) - Age Differences in Idol Worship 。 Youth Studies, 2007 (3), pp. 8-14.

[2] Yun Huifang. On Idolatry in Modernity Aesthetic Culture. Shaanxi Normal University, 2012, pp. I.

[3] (America) Louis Giannetti. tr. Jiao Xiongping. Understanding Movies, Xing jie book publishing company, 2007, pp. 312 